\title{
Papaya leaves juice as an alternative treatment for dengue fever
}

\section{Dear Editor,}

Dengue Fever (DF), a type of viral disease, is now almost an endemic to certain tropical and subtropical regions of the world. (Kadir et al., 2013; Senthilvel et al., 2013; Pigili et al., 2014; Abrao et al., 2015). According to Dengue Situation Update (Number 474) by World Health Organization, as on September 12, 2015, there were 85,488 dengue cases with 234 deaths reported in Malaysia for the year 2015. This is $21.5 \%$ higher compared to the same period in 2014 which is 70,337 cases. Dengue fever is transmitted by female Aedes aegypti mosquito carrying Flavivirus. The person who has been infected with dengue fever could be reinfected because the virus carries four different serotypes (Ahmad et al., 2011; Kadir et al., 2013). After being bitten, it would take three to fourteen days for early manifestation of symptoms such as fever, headache, rash, nausea, joint and musculosketel pain. If left untreated, it can cause blood plasma and vessel leakage, dropping of platelet count leading to dengue haemorrhagic fever (DHF) (Kadir et al., 2013; Pigili et al., 2014). Further severe development of DHF will lead to dengue shock syndrome (DSS) which is associated with high mortality rate (Kadir et al., 2013; Sarala et al., 2014). Currently the newly available dengue vaccine is still not routinely administered to the general public. Normally, oral and intravenous fluids administration and antipyretics is recommended to control blood circulation and fever (Ahmad et al., 2011; Kadir et al., 2013; Pigili et al., 2014).

Traditionally, medicinal plant has been often used to treat numerous diseases including DF (Kadir et al., 2013; Sheikh et al., 2014). For centuries Carica papaya leaves obtained from papaya tree have been used in the folk medicine to combat DF, because it is considered to be an effective, safe and cheap remedy (Dharmarathna et al., 2013; Subenthiran et al., 2013). Many studies have revealed that $C$. papaya leaves has a lot of benefits such as anti-inflammatory agent, antitumor, antioxidant, nephroprotective, hepatoprotective, hypoglycemic, hypolipidaemic, anti-sickling properties in sickle cell disease and act as a vermifuge (Patil et al., 2013; Subenthiran et al., 2013; Sarala et

\section{Thimarul Huda Mat Nuri, Long Chiau Ming*}

Faculty of Pharmacy Level 11, FF 1 , Universiti Teknologi MARA (UiTM), Puncak Alam Campus, 42300 Puncak Alam, Selangor, Malaysia.

*Email: ming.long[at]bath.edu al., 2014; Siddique et al., 2014). Due to its' ability to exert therapeutics effects on human; numerous studies on $C$. papaya leaf have been conducted in order to evaluate its properties, safety and toxicity in human. The most prominent therapeutics effect of this herb is its ability to increase platelet count in patient with thrombocytopenia in DF. An open labeled randomized controlled trial conducted in a hospital located in Malaysia to investigate the effect of $C$. papaya leaves juice to increase the platelet count in patient with DF and DHF (Subenthiran et al., 2013). A total of 229 patients were recruited (111 and 117 patients were from the interventional and control group respectively) whereby the experimental subject were given fresh juice from 50 grams of $C$. papaya leaves once daily, 15 minute after breakfast for 3 consecutive days. The findings has shown a significant increase in platelet count in the intervention group after 40 hours and 48 hours of treatment (Subenthiran et al., 2013). Furthermore, in Karachi, Pakistan a case report showed that a medical student with symptom of DF was given $150 \mathrm{~mL}$ of papaya leaf extract once daily for 5 consecutive days and a continuous rise in platelet by the end of the fifth day was recorded (Siddique et al., 2014). Another study in Karachi, $50 \mathrm{~mL}$ of the extract papaya leaf was given to a taxi driver diagnosed with DF twice daily for 5 days; a steady increment in platelet count and white blood cell were also shown (Siddique et al., 2014).

The occurrences claim the juice of papaya leaves in treating dengue's fever are mainly popularised via mass media or social media. In fact, there is no substantial scientific study to provide evidence that this juice can actually heal dengue fever. It is worth noting that some studies have shown that the papaya leaves juice did not contribute to platelet count increment in patients with DF. However it is still people's preference to use it to combat dengue fever since there is no exact medicine for it and in fact, there is no side effects are seen in a patient who consumes this juice. It can be considered safe because it does not affect any vital organs like kidney, heart and liver. However, it is still premature to recommend widely its use to all patients with DF as more concrete clinical findings are needed to support its use.

Acknowledgement: This work was supported by Research Acculturation Grant Scheme: RAGS/1/2015/SG0/UITM/03/10. The authors would like to express their gratitude to the Ministry of 
Higher Education, and Universiti Teknologi MARA (UiTM), Malaysia for financial support for this research.

\section{REFERENCES}

Abrao, EP, Esposito, DL, Lauretti, F, and Fonseca, BA. Dengue vaccines: what we know, what has been done, but what does the future hold? Rev Saude Publica, 2015; 49: 1-6.

Ahmad, N, Fazal, H, Ayaz, M, Abbasi, BH, Mohammad, I, and Fazal, L. Dengue fever treatment with Carica papaya leaves extracts. Asian Pac J Trop Biomed, 2011; 1: 330-333.

Dharmarathna, SLCA, Wickramasinghe, S, Rajapakse, PVJ, Waduge, RN, and Kularatne, SaM. Does Carica papaya leaf-extract increase the platelet count? An experimental study in a murine model. Asian Pac J Trop Biomed, 2013; 3: 720-724.

Kadir, SLA, Yaakob, H, and Zulkifl, RM. Potential anti-dengue medicinal plants: a review. J Nat Med, 2013; 67: 677-689.

Patil, S, Shetty, S, Bhide, R, and Narayanan, S. Evaluation of platelet augmentation activity of Carica papaya leaf aqueous extract in rats. J Pharmacogn Phytochem, 2013; 1: 57-60.

Pigili, RK and Runja, C. Medicinal plants used in dengue treatment: An overview. Int J Chem Nat Sci, 2014; 2: 70-76.

Sarala, N and Paknikar, SS. Papaya extract to treat dengue: a novel therapeutic option? Ann Med Health Sci Res, 2014; 4: 320-324.
Senthilvel, P, Lavanya, P, Kumar, KM, Swetha, R, Anitha, P, Bag, $\mathrm{S}$ et al. Flavonoid from Carica papaya inhibits NS2B-NS3 protease and prevents Dengue 2 viral assembly. Bioinformation, 2013; 18: 889-895.

Sheikh, N, Younas, N, and Akhtar, T. Effect of Carica papaya leaf formulation on hematology and serology of normal rat. Biologia, 2014; 60: 139-142.

Siddique, O, Sundus, A, and Ibrahim, MF. Effects of papaya leaves on thrombocyte counts in dengue--a case report. J Pak Med Assoc, 2014; 64: 364-366.

Subenthiran, S, Choon, TC, Cheong, KC, Thayan, R, Teck, MB, Rmuniandy, PK et al. Carica papaya leaves juice significantly accelerates the rate of increase in platelet count among patients with dengue fever and dengue haemorrhagic fever. Evid Based Complement Alternat Med, 2013; 2013: Article ID 616737, 616737 pages.

\section{How to cite this article:}

Nuri THM, Ming LC. Papaya leaves juice as an alternative treatment for dengue fever. J App Pharm Sci, 2016; 6 (03): $172-173$. 